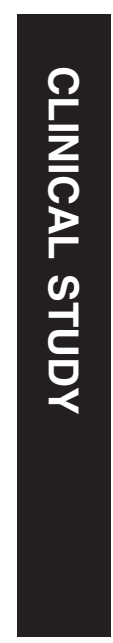

\title{
Accuracy and reliability of IOL master and A-scan immersion biometry in silicone oil-filled eyes
}

Department of Ophthalmology, Faculty of Medicine, Chiang Mai University, Chiang Mai, Thailand

Correspondence:

P Kunavisarut, Department of Ophthalmology, Faculty of Medicine, Chiang Mai University, 110 Intawaroros Road, Chiang Mai 50200, Thailand

Tel: +6653945512 3;

Fax: + 6653946121 .

E-mail: pkunavis@mail.med. cmu.ac.th

Received: 11 January 2012 Accepted in revised form: 6 July 2012

Published online: 10 August 2012

\section{Abstract}

Purpose To compare the accuracy and reliability of intraocular lens (IOL) master and A-scan immersion biometry in silicone oil (SO)-filled eyes.

Methods A prospective, consecutive, nonrandomized study was performed in 34 SO-filled eyes of 34 patients, who underwent a pars plana vitrectomy, with SO removal and cataract surgery, as well as IOL implantation. Both IOL master and immersion A-scan were performed to measure the axial length (AXL) before SO removal. Three months after removal of the SO, AXL measurements using IOL master and refraction was performed. Accuracy of the two techniques was determined by a mean postoperative $\mathrm{AXL}$ using an IOL master and reliability was determined by mean actual postoperative refractive error. Results Preoperative mean AXL was $23.91 \pm 0.24 \mathrm{~mm}$ (range $21.33-28.61 \mathrm{~mm}$ ) and $23.71 \pm 0.59 \mathrm{~mm}$ (range 19.27-36.18 $\mathrm{mm}$ ) by IOL master and A-scan immersion, respectively. Postoperative mean AXL by IOL master was $23.90 \pm 0.23 \mathrm{~mm}$ (range $21.58-27.94 \mathrm{~mm}$ ), which showed a statistically significant difference from the preoperative mean AXL by A-scan immersion $(P=0.005)$. The AXL measurement by IOL master also was more accurate than A-scan immersion by Pearson's correlation $(0.966 v s \mathbf{0 . 4 1 0 )}$. For reliability of the two techniques, the predictive postoperative refractive error in A-scan immersion (mean $1.79 \pm 1.04 \mathrm{D}$, range -14.62 to $16.41 \mathrm{D})$ was greater than that in IOL master (mean $0.60 \pm 0.23 \mathrm{D}$, range -2.74 to $2.33 \mathrm{D}$ ), with a statistically significant difference $(P=0.049)$. Conclusion IOL master had more accuracy and less deviation in predictive postoperative
P Kunavisarut, P Poopattanakul, C Intarated and $\mathrm{K}$ Pathanapitoon

refractive error than A-scan immersion in SO-filled eyes.

Eye (2012) 26, 1344-1348; doi:10.1038/eye.2012.163; published online 10 August 2012

Keywords: A-scan immersion biometry; IOL master biometry; silicone oil-filled eyes

Introduction

Success in visual improvement of silicone oil (SO)-filled phakic-induced cataract or SO-filled aphakic eyes that require oil and/or cataract removal, and intraocular lens (IOL)

implantation in one operation to avoid further surgery, depends on an accurate axial length (AXL) measurement and a precise IOL power calculation. However, biometry in SO-filled eyes is difficult to perform and measurement may be unobtainable, due to inclusion of optical and sound attenuation in SO properties. ${ }^{1-8}$ Using conventional ultrasound biometry with immersion technique in SO-filled eyes has several disadvantages, ${ }^{8}$ such as a false longer eye from slow sound speed, error in measurement from multiple fluid interfaces, or poor penetration from sound absorption by oil.

New noncontact laser interference biometry or IOL master uses the method of partial coherence interferometry to measure the AXL, based on reflection of the interference signal of the retinal pigment epithelium. This technique is seen to be 10 times more accurate than the acoustic method in normal cataract eyes, with no other pathologies. ${ }^{9,10}$ It has been suggested that IOL master also is more precise and useful in problematic eyes, including high myopia, staphyloma, or SO-filled eyes. ${ }^{11,12}$ 
The purpose of this study was to compare the accuracy and reliability of A-scan immersion and IOL master biometry in SO-filled eyes.

\section{Materials and methods}

A total of 34 SO-filled eyes of 34 patients, who underwent a pars plana vitrectomy with SO (Oxane 5700 centistokes; Bausch \& Lomb Inc., Waterford, Ireland) removal between October 2008 and April 2011, were recruited into this prospective, consecutive, nonrandomized study. Patients with recurrent retinal detachment or other ocular problems, which may influence measurement of the AXL, such as corneal scar and an irregular surface, were excluded.

Before SO removal, keratometric measurements were taken using IOL master (Version 5.0; Carl Zeiss Meditec Ltd, Jena, Germany), then the AXL was measured using IOL master (SO-filled eyes program) and immersion A-scan (SO-filled eyes mode; Quantel Medical compact II Version 1.03; Quantel Medical SA, Cournon d'Auvergne, France). Three months after SO removal, AXL measurements were made using an IOL master (pseudophakic mode). At least five consecutive AXL measurements were acquired for both IOL master and immersion A-scan. Each measurement had to have a signal-to-noise ratio (SNR) of $>2$ for IOL master, and a $\mathrm{SD} \pm 0.05 \mathrm{~mm}$ for the immersion A-scan. The IOL power was calculated using the SRK-T formula targeting emmetropia.

Cataract removal was performed in 16 phakic eyes, using the classic phacoemulsification technique through superior clear corneal incision. The SO was removed through the pars plana sclerotomy using a standard method. A foldable acrylic or PMMA posterior chamber IOL was inserted in 15 eyes. In 18 aphakic eyes, the SO was removed using the same technique, and a foldable acrylic or PMMA posterior chamber IOL was inserted in 17 eyes. Two eyes (one each from the phakic and aphakic group) were left aphakic, because of the large difference of IOL power between the two techniques. These two eyes were excluded from determination of the postoperative refractive error.

Refraction was performed using an automated refractor at least 3 months postoperatively in order to stabilize the refraction.

Accuracy of the two techniques was evaluated in this study, with IOL master determining the mean postoperative AXL, and reliability was measured by mean actual postoperative refractive error using the following equation: Predictive error of each technique $=$ Predicted postoperative error by that technique - postoperative spherical equivalent of the refractive error.
This study was approved by a suitably constituted Ethics Committee from the institution where the work was undertaken, and it conforms to provisions of the Declaration of Helsinki.

Statistical analyses were performed using the Wilcoxon signed ranks test, Pearson's correlation, Pearson's

Chi-square test, Fisher's exact test, and logistic regression by the software package, SPSS 16.0 (SPSS Inc., Chicago, IL, USA). The statistical significance was set at $P<0.05$.

\section{Results}

In 34 eyes of 34 patients ( 22 males and 12 females), with an age range from 15 to 73 years (mean $51.8 \pm 13.3$ years), 16 were phakic and 18 aphakic lens status.

The preoperative mean AXL was $23.91 \pm 0.24 \mathrm{~mm}$ (range $21.33-28.61 \mathrm{~mm}$ ) and $23.71 \pm 0.59 \mathrm{~mm}$ (range 19.27-36.18 $\mathrm{mm}$ ) by IOL master and immersion A-scan, respectively, which demonstrated a statistically significant difference $(P=0.002)$.

The postoperative mean AXL by IOL master was $23.90 \pm 0.23 \mathrm{~mm}$ (range 21.58-27.94 $\mathrm{mm}$ ), with no statistically significant difference from the preoperative mean AXL by IOL master $(P=0.538)$, but it was significantly different to the preoperative mean AXL by immersion $\mathrm{A}$-scan $(P=0.005)$. When compared with the postoperative AXL, the preoperative AXL was more accurate by the IOL master than by the immersion method (0.966 vs 0.410, Pearson's correlation). In all, 33 eyes (97\%) in the IOL master group and $20(58.82 \%)$ in the immersion group had a preoperative AXL within \pm 1 SD of the postoperative AXL.

In the subgroup analysis, this study found that a preoperative AXL outside \pm 1 SD of the postoperative AXL was associated with an aphakic lens status $(P=0.001$; odds ratio 14.0; CI 2.37-82.72) and AXL $>25 \mathrm{~mm}(P=0.042$; odds ratio 6.75; CI 1.11-41) in the immersion group. However, there were no such associations in the IOL master group (Table 1). From multivariate analysis, a preoperative AXL outside \pm 1 SD of the postoperative AXL also was associated with aphakic lens status $(P=0.007$; odds ratio 21.95; CI 2.3-209.56) and AXL $>25 \mathrm{~mm}(P=0.047$; odds ratio 12.92; CI 1.03-162.02) in the immersion group.

Regarding the reliability of these two techniques, the predictive postoperative refractive error in the immersion group (mean $1.79 \pm 1.04 \mathrm{D}$, range -14.62 to $16.41 \mathrm{D})$ was more than that in the IOL master group (mean $0.60 \pm 0.23 \mathrm{D}$, range -2.74 to $2.33 \mathrm{D}$ ) with a statistically significant difference $(P=0.049)$. Nine eyes $(30 \%)$ in the IOL master and three (10\%) in the immersion group had a predictive postoperative refractive error within $\pm 0.5 \mathrm{D}$. Fifteen eyes (50\%) in 
Table 1 Factors associated with preoperative AXL within and outside \pm 1 SD of postoperative AXL

\begin{tabular}{|c|c|c|c|c|c|c|c|}
\hline & \multirow{2}{*}{ Total $\mathrm{N}=34$} & \multicolumn{2}{|c|}{$\begin{array}{l}\text { Preoperative AXL within } \\
\pm 1 \text { SD of postoperative AXL }\end{array}$} & \multicolumn{2}{|c|}{$\begin{array}{l}\text { Preoperative AXL outside } \\
\pm 1 \text { SD of postoperative AXL }\end{array}$} & \multicolumn{2}{|c|}{ P-value } \\
\hline & & IOL master & Immersion & IOL master & Immersion & IOL master & Immersion \\
\hline Median age (year) & 53 & 53.0 & 55.0 & 38.0 & 49.5 & $0.108^{\mathrm{a}}$ & $0.256^{\mathrm{a}}$ \\
\hline Male to female & $22: 12$ & 22:11 & $13: 7$ & $0: 1$ & $9: 5$ & 0.353 & $0.966^{\mathrm{a}}$ \\
\hline Aphakic status (eye) & $18(52.9 \%)$ & $18(54.5 \%)$ & $6(30 \%)$ & $0(0 \%)$ & $12(85.7 \%)$ & 0.471 & $0.001^{\mathrm{a}}$ \\
\hline AXL $>25 \mathrm{~mm}$ & $8(23.5 \%)$ & $7(21.2 \%)$ & $2(10 \%)$ & $1(100 \%)$ & $6(42.9 \%)$ & 0.235 & 0.042 \\
\hline Median preoperative $\mathrm{SNR}^{\mathrm{b}}$ & 118.05 & 118.3 & - & 79.7 & - & $0.419^{\mathrm{a}}$ & - \\
\hline Preoperative $\mathrm{SNR}^{\mathrm{b}} \leq 100$ & $14(41.2 \%)$ & $13(39.4 \%)$ & - & $1(100 \%)$ & - & 0.412 & - \\
\hline
\end{tabular}

Abbreviations: AXL, axial length; SNR, signal-to-noise ratio.

a Pearson's Chi-square test; Fisher's exact test was used in all other calculations.

${ }^{\mathrm{b}}$ Composite SNR.

Table 2 Factors associated with predictive postoperative refractive error within and outside $\pm 1 \mathrm{D}$

\begin{tabular}{|c|c|c|c|c|c|c|c|}
\hline & \multirow{2}{*}{ Total $\mathrm{N}=30^{\mathrm{a}}$} & \multicolumn{2}{|c|}{ Predictive error within $\pm 1 D$} & \multicolumn{2}{|c|}{ Predictive error outside $\pm 1 D$} & \multicolumn{2}{|c|}{ P-value } \\
\hline & & IOL master & Immersion & IOL master & Immersion & IOL master & Immersion \\
\hline Median age (year) & 53 & 53.0 & 53.0 & 51.0 & 51.0 & $0.500^{\mathrm{b}}$ & $0.747^{\mathrm{b}}$ \\
\hline Male to female & $20: 10^{\mathrm{a}}$ & $10: 5$ & $5: 4$ & $10: 5$ & $15: 6$ & $1.000^{\mathrm{b}}$ & $0.398^{\mathrm{b}}$ \\
\hline Aphakic status (eye) & $15(50 \%)$ & $6(40 \%)$ & $1(11.1 \%)$ & $9(60 \%)$ & $14(66.7 \%)$ & $0.273^{\mathrm{b}}$ & 0.014 \\
\hline $\mathrm{AXL}>25 \mathrm{~mm}$ & $7(23.3 \%)$ & $4(26.7 \%)$ & $2(22.2 \%)$ & $3(20 \%)$ & $5(23.8 \%)$ & 1.000 & 1.000 \\
\hline Median Pre-op SNR ${ }^{c}$ & 118.05 & 144.70 & - & 79.7 & - & $0.414^{\mathrm{b}}$ & - \\
\hline Preoperative SNR ${ }^{c} \leq 100$ & $12(40 \%)$ & $3(20 \%)$ & - & $9(60 \%)$ & - & $0.025^{\mathrm{b}}$ & - \\
\hline
\end{tabular}

Abbreviations: AXL, axial length; SNR, signal-to-noise ratio.

${ }^{a}$ Four excluded patients: no IOL implantation (two) and no target when autorefraction performed (two).

' Pearson's Chi-square test; Fisher's exact test was used in all other calculations.

${ }^{\mathrm{c}}$ Composite SNR.

the IOL master and nine (30\%) in the immersion group had a predictive postoperative refractive error within \pm 1 D. Twenty-two eyes (73.3\%) in the IOL master and fourteen $(46.7 \%)$ in the immersion group had a predictive postoperative refractive error within $\pm 2 \mathrm{D}$.

This study found that in the IOL master group, a predictive postoperative refractive error of $> \pm 1 \mathrm{D}$ was associated with the preoperative composite SNR of $<100$ ( $P=0.025$; odds ratio 6.0; CI 1.17-30.72). The aphakic lens status in the immersion group was associated with a predictive postoperative refractive error of $> \pm 1 \mathrm{D}$ $(P=0.014$; odds ratio $16.0 ; \mathrm{CI} 1.66-154.6)$ and $\pm 2 \mathrm{D}$ $(P=0.001$, odds ratio 26.0; CI 3.69-183.42) (Table 2).

\section{Discussion}

Previous studies ${ }^{13-19}$ demonstrated that the IOL master appears to be a feasible and satisfactorily accurate method for measuring AXL in patients with SO-filled eyes. This study revealed similar outcomes and provided acceptable results in all lens status or AXL.

When comparing between the IOL master and A-scan immersion, both techniques showed that they had statistical differences in the mean AXL and predictive postoperative refractive error for SO-filled eyes. This study found that the preoperative AXL measured by A-scan immersion (range 19.27-36.18 $\mathrm{mm}$ ) had a wider range than that measured by IOL master (range 21.33$28.61 \mathrm{~mm}$ ), and also a higher variable when compared with the postoperative AXL (range 21.58-27.94 mm). In addition, the postoperative and target refraction range differed between -14.62 and $16.41 \mathrm{D}$ in the A-scan immersion group and -2.74 and $2.33 \mathrm{D}$ in the IOL master group. These findings indicated that A-scan immersion biometry had a higher deviation. Factors of high deviation included an eye with AXL $>25 \mathrm{~mm}$ and aphakia status. SO-filled long eyes in the immersion A-scan measurement, particularly those with posterior staphyloma, may create errors in the estimated sound speed. Also, a false echo or artifact formation may be caused in aphakic eyes by multiple small emulsification droplets or a prolapse of the SO into the anterior chamber. $2,7,20$

This study demonstrated that the IOL master would be more accurate in SO-filled eyes with a preoperative composite SNR of $>100$. The composite SNR resulted from advanced technology, improving AXL measurement in the IOL master version 5.0, which 
combines several signals together and cancels statistical noise to obtain a significant peak in the signal. With this technology, the number of measurable patients can be increased. However, in some cases (10-17\%), 11,12 performance of the IOL master is impossible, because of limitations of the machine, such as dense media opacity (corneal or lens opacity), poor fixation by the patients, or no machine availability. A-scan immersion would be useful in these situations and is recommended by this study for confirming results from other techniques, especially because of its high deviation in aphakia or an eye with AXL $>25 \mathrm{~mm}$. The other techniques include use of the following:

(1) Preoperative AXL in that eye if macular on and scleral buckle is not used during surgery. ${ }^{1}$

(2) AXL in the available contralateral eye; without a history of anisometropia and no use of sclera buckle. ${ }^{6}$ Nepp J et al ${ }^{18}$ found an AXL difference of $0.4 \pm 1.3 \mathrm{~mm}$ (range $0-5.5 \mathrm{~mm}$ ) between the SO-filled and contralateral eye. If the AXL of the contralateral eye was used, $46 \%$ and $26 \%$ of the patients would have a refractive error within 1 and $>3 \mathrm{D}$, respectively. ${ }^{18}$

(3) Immersion B-guided biometry; Abu el einen et $a l^{21}$ found that ultrasound biometry using immersion B-mode was more accurate than contact A-mode in SO-filled eyes, because of the precise localization and identification of ocular interfaces.

Other techniques such as X-ray computed tomography, ${ }^{22}$ magnetic resonance imaging, ${ }^{23}$ intraoperative retinoscopy, ${ }^{24}$ or intraoperative biometry ${ }^{14,25}$ have been reported to give accurate results in measuring the AXL of SO-filled eyes, but they require more equipment.

If results are still in doubt or impossible to confirm, the two-step operation (SO removal and secondary IOL implantation) has been recommended.

Residents performing all measurements (both IOL master and immersion A-scan) was a limitation in this study, although they all had had experience in these procedures for more than 1 year or in more than 50 cases. Working with an immersion A-scan needs a skilled and experienced examiner, whereas IOL master is easier, with results less dependent on the examiner. This could result in a very high deviation in the immersion A-scan group. There is also an inter-observer variation in the measurements. Further study using a single skilled and experienced technician for the measurement is needed.

In conclusion, IOL master had more accuracy and less deviation in predictive postoperative refractive error than A-scan immersion in SO-filled eye, especially in eyes with a composite SNR of $>100$.

\section{Summary}

\section{What was known before}

- Silicone oil-filled eyes that needed visual improvement, necessitating oil and/or cataract removal, and intraocular lens implantation, but biometry in these eyes is difficult to perform and accuracy of measurements might affect on visual outcomes.

What this study adds

- IOL master had more accuracy and less deviation in predictive postoperative refractive error than A-scan immersion in SO-filled eye, especially in eyes with a composite SNR of $>100$ and provided acceptable results in all lens status or AXL.

\section{Conflict of interest}

The authors declare no conflict of interest.

\section{References}

1 Grinbaum A, Treister G, Moisseiev J. Predicted and actual refraction after intraocular lens implantation in eyes with silicone oil. J Cataract Refract Surg 1996; 22: 726-729.

2 Shugar JK, De Juan E Jr, McCuen BW, Tiedeman J, Landers MR III, Machemer R. Ultrasonic examination of the siliconefilled eye: theoretical and practical considerations. Graefe's Arch Clin Exp Ophthalmol 1986; 224: 361-367.

3 Murray DC, Potamitis T, Good P, Kirkby GR, Benson MT. Biometry of the silicone oil-filled eye. Eye 1999; 13: 319-324.

4 Smiddy WE, Loupe DN, Michels RG, Enger C, Glaser BM, deBustros S. Refractive changes after scleral buckling surgery. Arch Ophtalmol 1989; 107: 1469-1471.

5 Shioya M, Ogino N, Shinjo U. Changes in postoperative refractive error when vitrectomy is added to intraocular lens implantation. J Cataract Refract Surg 1997; 23: 1217-1220.

6 Frau E, Lautier-Frau M, Labetoulle M, Hutchinson S, Offret $\mathrm{H}$. Phacoemulsification combined with silicone oil removal though posterior capsulorhexis. Br J Ophthalmol 1999; 83: 1406-1407.

7 Hoffer KJ. Ultrasound velocities for axial eye length measurement. J Cataract Refract Surg 1994; 20: 554-562.

8 Ghoraba HH, El-Dorghamy AA, Atia AF, Yassin AI. The problems of biometry in combined silicone oil removal and cataract extraction. Retina 2002; 22: 589-596.

9 Rajan MS, Keilhorn I, Bell JA. Partial coherence laser interferometry vs conventional ultrasound biometry in intraocular lens power calculations. Eye 2002; 16: 552-556.

10 Drexler W, Findl O, Menapace R, Rainer G, Vass C, Hitzenberger CK et al. Partial coherence interferometry: a novel approach to biometry in cataract surgery. $A m \mathrm{~J}$ Ophthalmol 1998; 126: 524-534.

11 Burnham WP. Optical coherence biometry. In: Wallace RB III ed Refractive Cataract Surgery and Multifocal IOLs. Thorofare: Slack, 2001, pp 21-35.

12 Tehrani M, Krummenauer F, Blom E, Dick HB. Evaluation of the practicality of optical biometry and applanation ultrasound in 253 eyes. J Cataract Refract Surg 2003; 29: 741-746. 
13 Roessler GF, Huth JK, Dietlein TS, Dinslage S, Plange N, Walter $\mathrm{P}$ et al. Accuracy and reproducibility of axial length measurement in eyes with silicone oil endotamponade. $\mathrm{Br} J$ Ophthalmol 2009; 93: 1492-1494.

14 El-Baha SM, Hemeida TS. Comparison of trfractive outcome using intraoperative biometry and partial coherence interferometry in silicone oil-filled eyes. Retina 2009; 29: 64-68.

15 Wang K, Yuan MK, Jiang YR, Bao YZ, Li XX. Axial length measurements before and after removal of silicone oil: a new method to correct the axial length of silicone-filled eyes for optical biometry. Ophthalmic Physiol Opt 2009; 29: 449-457.

16 Parravano M, Oddone F, Sampalmieri M, Gazzaniga D. Reliability of the IOLMaster in axial length evaluation in silicone oil-filled eyes. Eye 2007; 21: 909-911.

17 Habibabadi HF, Hashemi H, Jalali KH, Amini A, Esfahani MR. Refractive outcome of silicone oil removal and intraocular lens implantation using laser interferometry. Retina 2005; 25: 162-166.

18 Nepp J, Krepler K, Jandrasits K, Hauff W, Hanselmayer G, Velikay-Parel $\mathrm{M}$ et al. Biometry and refractive outcome of eyes filled with silicone oil by satandardized echography and partial coherence interferometry. Graefe's Arch Clin Exp Ophthalmol 2005; 243: 967-972.

19 Dietlein TS, Roessler G, Lüke C, Dinslage S, Roters S, Jacobi $\mathrm{PC}$ et al. Signal quality of biometry in silicone oil-filled eyes using partial coherence laser interferometry. J Cataract Refract Surg 2005; 31: 1006-1010.

20 Murray DC, Durrani OM, Good P, Benson MT, Kirkby GR. Biometry of the silicone oil-filled eye: II. Eye 2002; 16: 727-730.

21 Abu el einen KG, Shalaby MH, El shiwy HT. Immersion B-guided versus contact A-mode biometry for accurate measurement of axial length and intraocular lens power calculation in siliconized eyes. Retina 2011; 31: 262-265.

22 Takei K, Sekine Y, Okamoto F, Hommura S. Measurement of axial length of eyes with incomplete filling of silicone oil in the vitreous cavity using $\mathrm{x}$ ray computed tomography. $\mathrm{Br} \mathrm{J}$ Ophthalmol 2002; 86: 47-50.

23 Bencic G, Marotti M, Loncar VL, Loncar VL, Petric I, Andrijevic-Derk B et al. Comparison of A-scan and MRI for the measurement of axial length in silicone oil-filled eyes. Br J Ophthalmol 2009; 93: 502-505.

24 Patwardhan AD, Azad R, Sharma Y, Chanana B, Tyagi J. Intraoperative retinoscopy for intraocular lens power estimation in cases of combined phacoemusification and silicone oil removal. J Cataract Refract Surg 2009; 35: 1190-1192.

25 El-Baha S, El-Samadoni A, Idris H, Rashad K. Intraoperative biometry for IOL power calculation at silicone oil removal. Eur J Opthalmol 2003; 13: 622-626. 